and for comparison I have plotted Brown's curve for the brass jet $W 3$ operated under a different gas pressure in a room quite different in size and character.

By kind permission of Dr. Ewing my experiments were carried out in a very heavily lagged room in the Department of Education for the Deaf in the University of Manchester, and Dr. T. S. Littler kindly assisted in taking the readings. Though this set of observations and Savić's cannot be held to prove Brown's theory, they do suggest that his results were not fortuitous.

Department of Physics,

University of Manchester.

2 Nature, 108, 533 (1921).

'Phil. Mag., 13, 161 (1932).

'Proc. Phys. Soc., 49, 519 (1937)

'Proc. Phys. Soc., 53, 329 (1941).

SNATURE, 147, 241 (1941).

\section{Dealkylation of Phenolic Ethers}

SEVERAL methods have been reported in the literature for the dealkylation of ethers; for example, with hydrobromic acid' ${ }^{1}$, hydriodic acid ${ }^{2}$, aluminium chloride $^{3}$, aluminium bromide ${ }^{4}$, alkyl magnesium iodide ${ }^{5}$, aldsol ${ }^{6}$, piperidine or moist pyridine ${ }^{7}$, aniline hydriodide in aniline ${ }^{8}$, and magnesium iodide. Some of these methods appear to be of specific nature only.

I have found that although piperidine and moist pyridine failed to demethylate $\beta$-methoxynaphthalene at their boiling points, yet partial demethylation occurred when the reaction was carried out in a sealed tube to $250-300^{\circ}$. Aniline hydriodide in aniline, however, did not effect this demethylation even when heated to $250-270^{\circ}$. The use of quinoline hydriodide or aniline hydriodide in boiling quinoline instead of aniline gave satisfactory results. Although other solvents such as dry pyridine, diphenyl-amine, phthalimide and acetanilide, but not dimethylaniline or $\alpha$-methylnaphthalene, could replace quinoline, yet the extent of demethylation is much less. The following ethers have been similarly demethylated: 4-methoxy-diphenyl, 6-bromo-2-methoxynaphthalene, 4-nitro-2-methoxynaphthalene, 2- and 4methoxy-1-benzoylnaphthalene. The mechanism of the reaction is under investigation.

Fouad I. University, FAWZy GHaLI BADdaR.

Faculty of Science,

Abbassia, Cairo.

${ }^{1}$ Araki, C., and Hoshi, Y., J. Chem. Soc. Japan, 59, 278 (1938).

- Howell, W., and Robertson, A., J. Chem. Soc., 588 (1936).

'Gulati, K. C., and Venkataraman, K., J. Chem. Soc., 267 (1936).

‘Pfeiffer, P., and Loewe, W., J. Prakt. Chem., 147, 293 (1937).

'Serini, A., and Steinruck, K., Naturwissen., 25, 682 (1937).

-Takagi, S., and Ishimasa, S., J. Pharm. Soc. Japan, No. 517, 266 (1925).

'Cahn, R. S., J. Chem. Soc, 1121 (1931).

'Asahina, Y., and Yosioka, I., Ber., 69, B, 1367 (1936).

\section{Experimental Observations on the Relation between Leaf Development and Stelar Morphology in Species of Dryopteris}

The classical accounts of vascular structure in leptosporangiate ferns show clearly that the interruption of the conducting cylinder of the shoot is associated with the 'insertion' of the leaf-traces, that is, the vascular strands of the petiole or leaf-base. Thus, in a solenostelic fern, a eross-section at the level where a leaf-base joins the shoot will show the presence of a leaf-gap; in other words, the vascular

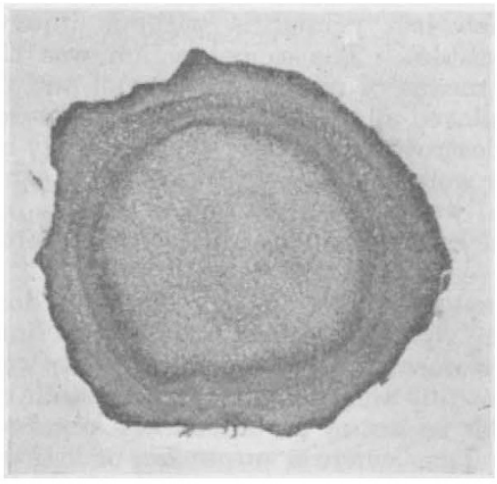

Fig. 1. Dryopteris aristata: TRANSVERSE SECTION SHOWING INDUCED SOLENOSTELE IN EXPERIMENTAL REGION OF SHOOT. $(\times, 4$.$) (PHOTO BY E. ASHBY.)$
(PHOSTEL

cylinder which would otherwise be continuous is interrupted by non-vascular tissue, usually parenchyma. In shoots where the leaf-gaps overlap, the vascular system becomes an open meshwork, or dictyostele, each individual strand being described as a meristele. Various tentative physiological explanations have been advanced to account for the development of these leaf-gaps. A considerable volume of literature also deals with the question as to what extent the vascular tissue of the shoot is of truly cauline origin, or alternatively, is a composite structure largely composed of decurrent leaf-traces. So far as I am aware, these problems have not been approached by direct experimental methods. The simple and easily repeatable technique, described below, has resulted in experimental observations of very considerable interest.

The distal ends of erect shoots of Dryopteris aristata and $D$. filix-mus were completely defoliated and the scales removed so that the terminal region was left 'naked'. The apical meristematic cone was left intact, but the minute leaf primordia round its base were destroyed by needle-puncturing. For this purpose a Zeiss micromanipulator was used, the material being observed under a binocular microscope. Alternatively, by using a needle on its side and gently moving it over the surface of the shoot away from the base of the apical cone, it was possible to 'smooth

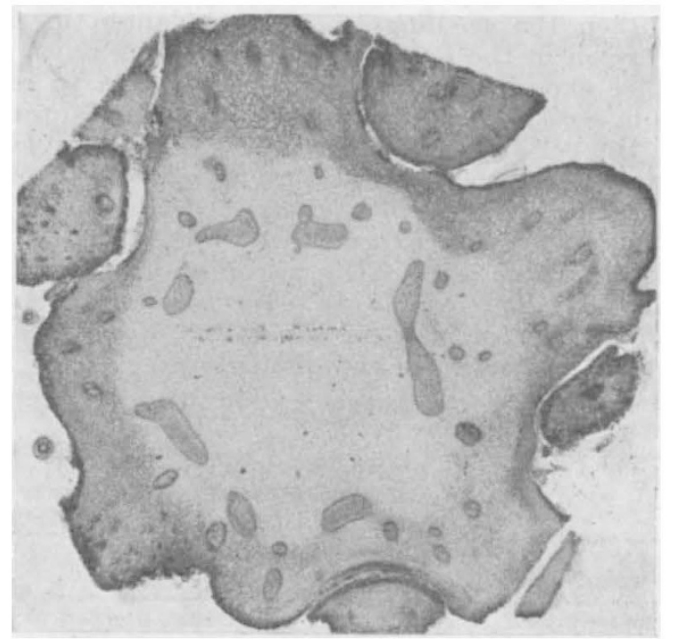

Fig. 2. TYPICAL DICTYOSTELE AND LEAF BASES IN THE UNTREATED REGION BELOW. $(x$ 4.) (PHOTO BY E. ASHBY.) 